\title{
Genetic education and the challenge of genomic medicine: development of core competences to support preparation of health professionals in Europe
}

\author{
Heather Skirton ${ }^{\star, 1}$, Celine Lewis ${ }^{1,2}$, Alastair Kent ${ }^{2}$ and Domenico A Coviello ${ }^{3}$, the members of Eurogentest \\ Unit 6 and ESHG Education Committee ${ }^{4}$
}

The use of genetics and genomics within a wide range of health-care settings requires health professionals to develop expertise to practise appropriately. There is a need for a common minimum standard of competence in genetics for health professionals in Europe but because of differences in professional education and regulation between European countries, setting curricula may not be practical. Core competences are used as a basis for health professional education in many fields and settings. An Expert Group working under the auspices of the EuroGentest project and European Society of Human Genetics Education Committee agreed that a pragmatic solution to the need to establish common standards for education and practice in genetic health care was to agree to a set of core competences that could apply across Europe. These were agreed through an exhaustive process of consultation with relevant health professionals and patient groups. Sets of competences for practitioners working in primary, secondary and tertiary care have been agreed and were approved by the European Society of Human Genetics. The competences provide an appropriate framework for genetics education of health professionals across national boundaries, and the suggested learning outcomes are available to guide development of curricula that are appropriate to the national context, educational system and health-care setting of the professional involved. Collaboration between individuals from many European countries and professions has resulted in an adaptable framework for both pre-registration and continuing professional education. This competence framework has the potential to improve the quality of genetic health care for patients globally.

European Journal of Human Genetics (2010) 18, 972-977; doi:10.1038/ejhg.2010.64; published online 5 May 2010

Keywords: genomics; professional education; competence

\section{INTRODUCTION}

The effect of genomics on health care

The science of genomics is increasingly important to health-care provision in Europe as an estimated 30 million people now suffer from genetic diseases within the enlarged European community. ${ }^{1}$ The number of genetic tests being performed is changing rapidly, ${ }^{2,3}$ with a concurrent increase in the number of individuals who have to make decisions about testing that may profoundly influence not only their own lives, but also the lives of their family members. Genetic health care has been offered for several decades by specialist doctors, nurses and counsellors working in the context of genetics clinics, but the relatively new science of genomics (interaction between genes and the environment that influence health and disease) is also having an effect on health-care delivery. ${ }^{4}$ As understanding of the effect of gene variation on the complex or common diseases increases, knowledge of genetics is needed by health professionals to practise in the current genomic era. ${ }^{5}$ Moreover, the science of pharmacogenomics is steadily affecting the quality of health care. Genetic tests, such as those for CYP2C9/VKORC1 polymorphisms before administration of warfarin, ${ }^{6}$ are now being used to increase patient safety and the efficacy of drug therapy. Within families, counselling for both patients and their relatives with respect to adverse drug reactions can also be vital and requires knowledge of genetics and pharmacogenomics by primary health-care providers. It is therefore essential that health professionals are appropriately prepared to deliver such patient care.

Need for health professional competence in genetics

To respond to the needs of patients, health-care providers require a set of core skills and knowledge to evaluate family history and to recognize clinical findings that indicate increased genetic risk. It is clear that specialist genetic services will continue to be needed to provide genetic diagnosis and counselling for rare inherited conditions. Moreover because of the advances in technology related to diagnostic and therapeutic interventions for genetic conditions, it is possible that demand for specialist genetic services will grow. However, practitioners in both secondary and primary care will need to be equipped to deal with initial patient enquiries, to have an awareness of the potential implications of family history, to offer information related to their specific area of practice and to refer individuals or families appropriately to other health-care providers, including specialist genetic services. A distinction must also be made between providing basic genetic information and enabling the patient to place

${ }^{1}$ Faculty of Health, University of Plymouth, Taunton, Somerset, UK; ${ }^{2}$ Genetic Interest Group, UK; ${ }^{3}$ Fondazione IRCCS, Ospedale Maggiore Policlinico, Mangiagalli e Regina Elena, Milan, Italy

*Correspondence: Professor H Skirton, Faculty of Health, University of Plymouth, Wellington Road, Taunton TA1 5YD, UK. Tel: +44 1823 366911 ; Fax: +44 1823 366901 ; E-mail: heather.skirton@plymouth.ac.uk

${ }^{4}$ Members of the Eurogentest Unit 6 and Education Committee of the ESHG are listed in the Appendix.

Received 17 December 2009; accepted 31 March 2010; published online 5 May 2010 
that information into a usable context through the specialized process of genetic counselling, which is the remit of trained genetic specialists.

\section{Primary care}

The evidence indicates that many patients with a genetic concern will approach a primary-care practitioner in the first instance, and general practitioners have indicated that they are keen to access more training in genetics. ${ }^{7}$ Family practitioners surveyed by Burke et al ${ }^{8}$ indicated they felt genetics was an important topic for practice, but that their educational preparation was lacking. Evidence that additional education in genetics is required for nurses has been provided in a study ${ }^{9}$ that showed that although nurses and midwives perceived a need for genetics knowledge, they felt underprepared for practice in relation to genetics. Similarly, in a study of graduates of six allied health professional training programs, Christianson et al ${ }^{10}$ showed that allied health professionals were engaging in tasks related to genetic health care with their clients (such as discussing patterns of inheritance), but $78 \%$ of those studied did not believe that they were sufficiently prepared during training to undertake these tasks.

\section{Secondary care}

The question of genetic contribution to a disease may also arise in the context of secondary care. Recent work by Burke et $a l^{8}$ indicated that preparation of doctors in a number of specialist areas (neurology, cardiology and dermatology) is still inadequate in terms of knowledge of genetics that would be directly relevant to their field of practice. A Working Party on genetics in haemophilia care strongly suggested that nurses working in this specialty have relevant education in genetics to enable them to support patients and their families appropriately, ${ }^{11}$ and the need for oncology nurses to develop competence in genetics has also been suggested. ${ }^{12}$ In recent years, dentists have also been identified as practitioners who have input into diagnosis and management of genetic disease and are therefore also required to develop competences in this area. ${ }^{13}$ Although it is essential that specialists trained in genetics continue to provide genetic diagnosis and counselling for a number of the rare inherited conditions, practitioners in both secondary and primary care will need to be equipped to deal with initial patient enquiries, to have an awareness of the potential implications of family history, to offer information related to their specific area of practice and to refer individual or families appropriately to other health-care providers, possibly specialist genetic services.

\section{Tertiary care (genetics specialists)}

The status of clinical genetics as a specialty in Europe varies from country to country. In several countries, clinical genetics is officially recognized as a specialty, with a specific and prescribed medical training in clinical genetics in departments of genetics or genetic laboratories. However, at present it is not identified as a medical specialty at the European level. The European Society of Human Genetics (ESHG) is working to ensure that medical genetics is recognized as a European specialty under European Commission Directive 2005/36/EC to facilitate development of genetic health care in the European community. A core curriculum on genetics for medical education has been drafted.

\section{Rationale for a set of core competences in Europe}

The Education Committee of the ESHG (www.eshg.org), working collaboratively with Unit 6 (Education) of the EuroGentest project (www.eurogentest.org), undertook an extensive literature review focussing on the current state of preparation for health professionals in Europe. There are significant differences in the way in which professional education is delivered and practice is regulated across the countries of Europe. Although a minimum standard for practice is required, setting curricula was not viewed as a practical way of ensuring that those standards were met, given the differences in systems. The establishment of core competences is currently being used as a basis for health professional education in many other fields and settings. ${ }^{14-16}$ It was therefore agreed that a pragmatic and workable solution would be to describe and agree, by consensus, a set of core competences that could apply to health professionals in Europe, whatever their national setting. This could provide an appropriate framework for establishing minimum standards of preparation for health-care professionals in genetics across national boundaries. Because of the dynamic nature of the field, practitioners at all levels of health care, primary, secondary and tertiary, require both preregistration and continuing education in genetics to ensure early diagnosis and prevention of disease. Because of the different levels of expertise required by the range of practitioners involved in delivering acceptable genetic health care, a set of competences at each level is also required.

\section{MATERIALS AND METHODS}

\section{Existing sets of core competences in genetics}

A level of professional education in genetics for some specific health professionals exists in many countries in Europe. However, few countries have established sets of core competences. In the United Kingdom, Kirk et all ${ }^{17}$ used an Expert Panel as part of a research project to define core competences in genetics for nurses, midwives and health visitors. The agreed set of genetic competences have been aligned to the general statements of competence that are required of each practitioner before registration with the Nursing and Midwifery Council, the statutory body responsible for standards of practice in nursing and midwifery. Although these apply to generalists, a different set of core competences ${ }^{18}$ is the basis of the registration system for specialist genetic nurses and genetic counsellors in the United Kingdom. In addition, in the United Kingdom, a competence framework describing a set of nine genetic activities that may be carried out by non-genetics health-care staff has been developed by the NHS National Genetics Education and Development Centre, Skills for Health and by a wide range of health-care professionals (www.geneticseducation.nhs.uk).

The National Coalition for Health Professions Education in Genetics (NCHPEG) was established in 1997 as an interdisciplinary group comprising leaders from over 120 health professional organisations, consumer and voluntary groups across the United States. This coalition has prepared core competencies (http://www.nchpeg.org/) recommending that all health professionals possess the core competencies in genetics to enable them to integrate genetics effectively and responsibly into their current practice. A consensus document sponsored by the NCHPEG, detailing the core competencies in genetics for general nurses in the United States and guidelines for development of nursing curricula, has now been ratified by a large number of nursing organisations, including the American Nurses Association and the International Society of Nurses in Genetics (http://64.78.6.122/resources/genetics_ competencies_092206.pdf).

\section{Setting the framework}

The aim of the project team was to produce a set of competences that could be applied across Europe to the range of health professionals involved in provision of genetic health care. Given the need to prepare a range of health-care professionals across the primary, secondary and tertiary care spectrum, and the need to set up a common framework for use in a European context, three groups of health professionals that require education and training in genetics were identified:

- Health-care professionals working in generalist settings

- Specialist health professionals (non-genetic)

- Specialists in genetics. 
It was agreed to use these groups as a framework for the work on development of sets of core competences. Each group requires a different level and depth of genetics education, and the classification has been adopted to enable the needs of each group to be addressed. In addition to setting for practice (generalist health care), specialist (non-genetic) and specialist genetic, it was agreed to divide the groups by professional background, with the main groups being medical, nursing/midwifery, dental and laboratory professionals. For each group, the project team agreed a list of competences and the learning outcomes associated with each competence.

For the purpose of the proposed framework, competences were defined as the set of behaviours that are expected by independent professionals, ${ }^{19}$ which include using communication skills as well as knowledge and clinical reasoning. ${ }^{20}$ The competence therefore describes the behaviour expected by the professional in the particular setting in which he or she works. Learning outcomes are used to dissect the competence into more manageable units that can be the focus of learning. Each learning outcome encompasses particular knowledge, skills or attitudes.

\section{RESULTS}

In 2006, the Education Committee of the ESHG and other experts of Unit 6 (Education) of the EuroGentest project prepared a draft document 'Core competences in genetics for health professionals in Europe' that was sent to a larger group of experts in Europe (including patient organisations) to stimulate further inputs. A workshop was held in 2006, in which the amended draft was discussed among 55 participants from 16 countries. In 2007, the recommended competences documents were circulated to a wide range of health professionals across Europe, resulting in the current documents. Box 1 includes the brief competence statements for professionals who are working as generalists or who specialize in a field other than genetics. Core competences for those who specialize in genetics are listed in Box 2. An executive summary, background document and full competences and learning outcomes are available on the web sites of the ESHG and EuroGentest (www.eurogentest.org).

\section{Box 1 Core competences for generalists and those specializing in a field other than genetics}

General practitioner

1. Identify individuals who may have or may carry a genetic condition.

2. Communicate information about genetics in an understandable, comprehensible and sensitive way, helping patients to make informed decisions and choices about their care.

3. Manage patients with genetic conditions, using accepted guidelines.

4. Obtain specialist help and advice on inherited conditions.

5. Coordinate care with other primary-care professionals, geneticists and other appropriate specialists.

6. Offer appropriate psychological and social support to patients and families affected by a genetic condition.

General nurse/midwife

1. Identify individuals who might benefit from genetic information and services.

2. Tailor genetic information and services to the individual's culture, knowledge and language.

3. Uphold the rights of all individuals to informed decision making and voluntary action.

4. Demonstrate knowledge of the role of genetic and other factors in health and disease.

5. Demonstrate a knowledge and understanding of the utility and limitations of genetic testing and information.

6. Recognize the limitation of one's own genetic expertise.

Medical specialist in fields other than genetics

1. Identify individuals with or at risk of a genetic condition.

2. Communicate information about genetics in an understandable, comprehensible and sensitive way, helping patients to make informed decisions and choices about their care.

3. Be familiar with the uses and limitations of genetic testing and be able to use genetic testing appropriately.

4. Manage patients with genetic conditions, using accepted guidelines.

5. Obtain specialist help and advice on inherited conditions, as appropriate.

6. Coordinate care with primary care professionals, geneticists and other appropriate specialists.

7. Offer appropriate psychological and social support to patients and families affected by a genetic condition.

Specialist nurse, specialist midwife and specialist allied health professional

1. Identify individuals who might benefit from genetic information and services.

2. Tailor genetic information and services to the individual's culture, knowledge and language.

3. Uphold the rights of all individuals to informed decision making and voluntary action.

4. Demonstrate knowledge of the role of genetic and other factors in health and disease.

5. Demonstrate a knowledge and understanding of the utility and limitations of genetic testing and information.

6. Recognize the limitation of one's own genetic expertise.

7. Obtain and communicate credible current information about genetics for self, clients and colleagues.

\section{Specialist dentist}

1. Identify patients with a genetic condition.

2. Communicate information about genetics in an understandable, comprehensible and sensitive way, helping patients to make informed decisions and choices about their care.

3. Manage patients with genetic conditions, using accepted guidelines.

4. Obtain specialist help and advice on inherited conditions, as appropriate.

5. Coordinate care with primary care professionals, geneticists and other appropriate specialists.

6. Offer appropriate psychological and social support to patients and families affected by a genetic condition. 


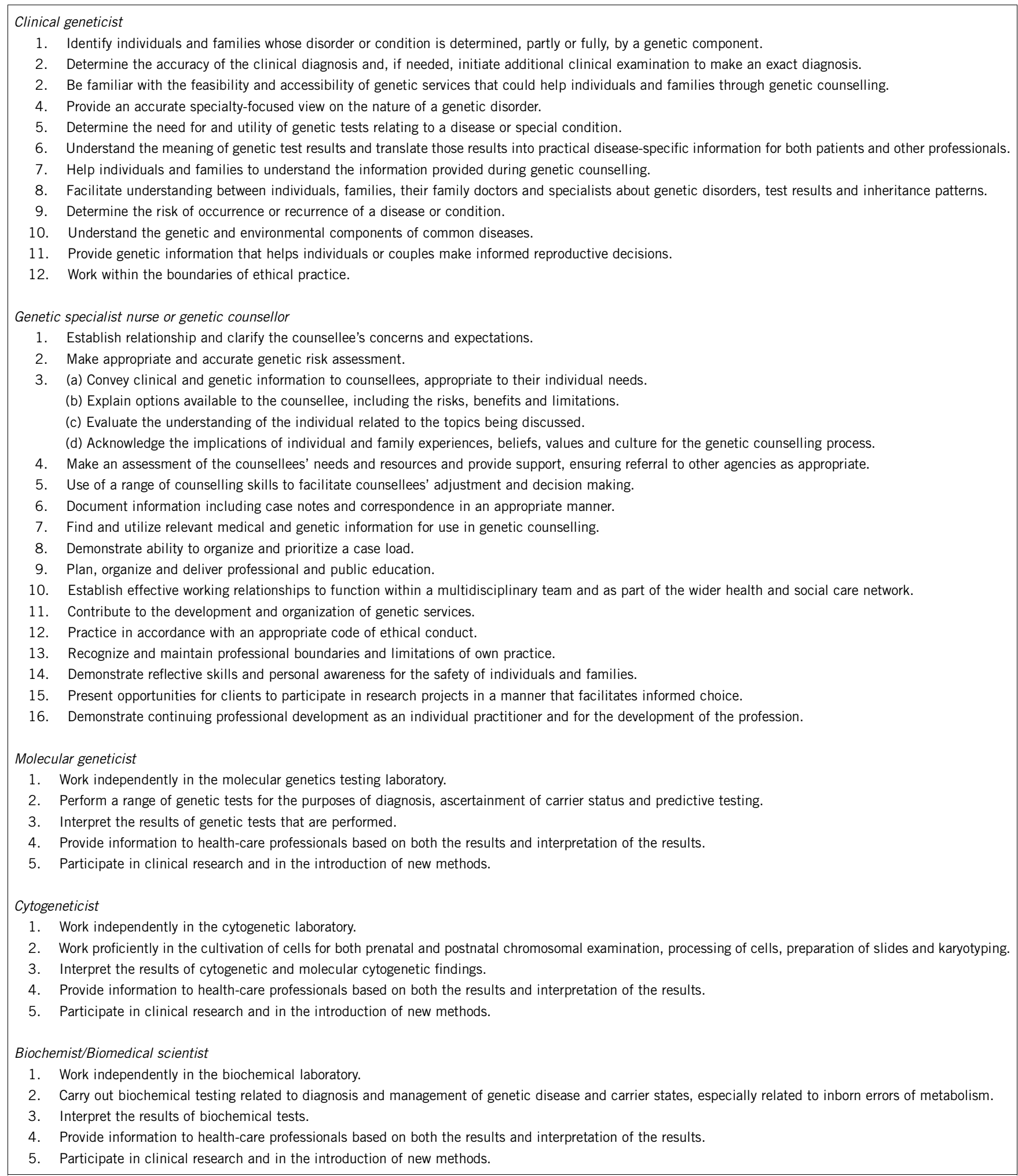

\section{DISCUSSION}

The aim of these sets of competences is not to unify the existing genetic services across national boundaries but, by achieving consensus, to help countries to adjust their education and genetic service delivery systems for the future, according to a coherent set of standards. The consensus document will guide the states of Europe with regard to how the new generation of health professionals should be educated in the post-genomic era and how genetic training should be built into higher education systems. National societies and professional and patient groups are invited to use this document to refine 
the competences, learning outcomes and curricula consistent with their own needs. We are actively seeking inputs and would be willing to meet with professional and patient groups in different countries to receive feedback and to support development of competences that are applicable to the local and regional situation.

However, it must be appreciated that each genetic counselling situation is context specific and the appropriate person to provide care may vary according to the precise family circumstances, type of disease and level of expertise of the professional. As a general rule, counselling accompanying predictive and prenatal testing will be offered by trained genetics specialists (medical and non-medical). However, counselling for a range of other genetic/genomic tests may be undertaken by other health professionals.

These core competences provide a basis for education, but much work is ahead to ensure that curricula, courses and educational opportunities are available to support health professionals in achieving competence. In the era of personalized medicine, the role of genetic specialists will increasingly encompass education of other health professionals. $^{21}$ The ESHG is aware of this pressing need and has resolved to invest more heavily in education. Current ESHG initiatives include working collaboratively with national societies to (1) increase support for specific genetics courses in several EU countries, (2) develop courses to 'train the trainers' so that education can be available to a wider range of professionals, many of whom may be fluent in a language other than their mother tongue and (3) support development of e-learning resources. It should be noted that these core competences relate to clinical and laboratory health services, rather than public health. A Working Group of Public Health Genetics (PHG) on Policy Development for Education and Training in Genomics for Population Health is currently addressing the core competences required by Public Health professionals and these will be published by that group.

The Education Committee of ESHG is actively interacting with other professional organisations of heath-care providers. Current initiatives of collaboration are active with the NHS National Genetics Education and Development Centre, Birmingham, UK, the Association for Medical Education in Europe (AMEE), European Accreditation Council for CME (EACCME), Union Européenne des Médecins Spécialistes (UEMS; European Union of Medical Specialists; www.uems.net) and the Public Health Genetics Network (PHGen). This type of collaboration is essential to ensure that a set of competences that fulfils the needs and relates appropriately to each professional group is created.

Ultimately, it is essential that genetics is integrated into the curricula for professional education. The learning outcomes are available, if required, to guide the development of curricula that are appropriate to the national context, educational system and health-care setting of the professional involved. We are aware that in some countries there are curricula that have already been devised to educate and train health professionals in genetics. It is suggested that these curricula are assessed against the competences and learning outcomes for particular groups of professionals to ensure that all the requisite areas are covered.

The synergy created by collaboration between individuals from many European countries and professions has resulted in a framework of competences on which pre-registration and continuing professional education can be based. This is an emerging field and the establishment of professional standards of care must be viewed as a dynamic process. Ultimately, each professional group in each country must take responsibility for development of professional and educational standards in genetic health care that apply to local needs. However, it is hoped that the work presented in this study provides a foundation for quality patient care.

\section{CONFLICT OF INTEREST}

The authors declare no conflict of interest.

\section{ACKNOWLEDGEMENTS}

We thank all members of the Unit 6 Experts Group who contributed at workshops in Porto, Portugal, in 2006 and Milan, Italy, in 2007. We are also grateful for all comments received from members of the European Society for Human Genetics and the EuroGentest project teams. This document was written by Heather Skirton and Celine Lewis with the support of Alastair Kent and Domenico Coviello. This study was funded by the EuroGentest Network of Excellence Project 2005 - EU Contract no. FP6-512148.

1 Cassiman JJ: Research network: EuroGentest-a European Network of Excellence aimed at harmonizing genetic testing services. Eur J Hum Genet 2005; 13: 1103-1105.

2 Schmidtke J, Pabst B, Nippert I: DNA-based genetic testing is rising steeply in a national health care system with open access to services: a survey of genetic test use in Germany, 1996-2002. Genet Test 2005; 9: 80-84.

3 Constantin CM, Faucett A, Lubin IM: A primer on genetic testing. J Midwifery Womens Health 2005; 50: 197-204.

4 Kraft P, Yen YC, Stram DO, Morrison J, Gauderman WJ: Exploiting gene-environment interaction to detect genetic associations. Hum Hered 2007; 63: 111-119.

5 Guttmacher AE, Porteous ME, Mclnerney JD: Educating health-care professionals about genetics and genomics. Nat Rev 2007; 8: 151-157.

6 Caldwell MD, Berg RL, Zhang KQ et al: Evaluation of genetic factors for warfarin dose prediction. Clin Med Res 2007; 5: 8-16.

7 McCann S, Macauley D, Barnett Y: Genetics and genetic testing: are GPs likely to attend training courses? J Cancer Educ 2004; 19: 225-226.

8 Burke S, Stone A, Bedward J, Thomas H, Farndon P: A 'neglected part of the curriculum' or 'of limited use'? Views on genetics training by nongenetics medical trainees and implications for delivery. Genet Med 2006; 8: 109-115.

9 Burke S, Kirk M: Genetics education in the nursing profession: literature review. J Adv Nurs 2006; 54: 228-237.

10 Christianson CA, McWalter KM, Warren NS: Assessment of allied health graduates' preparation to integrate genetic knowledge and skills into clinical practice. J Allied Health 2005; 34: 138-144.

11 Ludlam CA, Pasi KJ, Bolton-Maggs P et al: Smith M UK Haemophilia Centre Doctors' Organisation.: A framework for genetic service provision for haemophilia and other inherited bleeding disorders. Haemophilia 2005; 11: 145-163.

12 Lewis JA, Calzone KM, Jenkins J: Essential nursing competencies and curricula guidelines for genetics and genomics. MCN Am J Matern Child Nurs 2006; 31: $146-153$.

13 Dudlicek LL, Gettig EA, Etzel KR, Hart TC: Status of genetics education in US dental schools. J Dent Educ 2004; 68: 809-818.

14 Lin IB, Beattie N, Spitz S, Ellis A: Developing competencies for remote and rural senior allied health professionals in Western Australia. Rural Remote Health 2009; 9: 1115.

15 Walton MM, Elliott S: Improving safety and quality: how can education help? Med J Aust 2006; 184 (10 Suppl): S60-S64.

16 Wold JL, Gaines SK, Leary JM: Use of public health nurse competencies to develop a childcare health consultant workforce. Public Health Nurs 2006; 23: 139-145.

17 Kirk M, McDonald K, Longley M, Anstey S: Fit for Practice in the Genetics Era: Defining What Nurses, Midwives and Health Visitors Should Know and be Able to do in Relation to Genetics. University of Glamorgan: Pontypridd, 2003.

18 Skirton H, Kerzin-Storrar L, Patch C et al: Genetic counsellors - a registration system to assure competence in practice in the United Kingdom. Commun Genet 2003; 6: $182-183$.

19 Plasschaert A, Boyd M, Andrieu S: Development of professional competences. Eur J Dent Educ 2002; 6 (Suppl 3): 33-44.

20 Epstein RM, Hundert EM: Defining and assessing professional competence. JAMA 2002; 287: 226-235.

21 Kirk M, Lea D, Skirton H: Genomic health care: is the future now? Nurs Health Sci 2008; 10: 85-92. 


\section{APPENDIX}

Members of the Eurogentest Unit 6 and Education Committee of the ESHG:

Agnes Bloch-Zupan, DChD, PhD, HDR, MCU-PH

Faculte de Chirurgie Dentaire de Strasbourg, Universite Louis Pasteur,

Hopital Civil, Strasbourg Cedex France.

Francoise Clerget Darpoux, PhD, INSERM U535,

'Genetique Epidemiologique et Structure des Populations

Humaines',

Hopital Paul Brousse, Batiment Leriche, Villejuif Cedex, France.

Martina Cornel, MD, PhD, Professor of Community

Genetics, VU University Medical Center, Amsterdam, The

Netherlands.

Celia DeLozier, PhD, Director Clinical Services

Genetic Medicine Central California,

Fresno, CA, USA.

Peter Farndon, MD, PhD, Director, NHS Genetics Education and Development Centre,

Clinical Genetics Unit, Birmingham Womens Hospital,

Edgbaston, Birmingham, UK.

Peter Goetz, Professor of Medical Genetics,

Czech Instititue for Postgraduate Education of Physicians.

Institute of Biology and Medical Genetics (IBMG), Prague, Czech

Republic.

Shirley Hodgson, Professor of Cancer Genetics, Honorary,

Consultant in Clinical Genetics, Department of Clinical
Genetics, St George's Hospital, University of London, London, UK.

Gunnar Houge, MD, PhD,

Department of Anatomy and Cell Biology,

Bergen, Norway.

Maj Hulten, Professor of Reproductive Genetics,

Warwick Medical School, The University of Warwick,

Coventry, UK.

Gyorgy Kosztolanyi, Professor of Human Genetics,

Director of the Department of Medical Genetics,

University of Pecs, Hungary.

Vaidutis Kucinskas, Professor of Medical Genetics,

Department of Human and Medical Genetics, Faculty of

Medicine,

Vilnius University, Vilnius, Lithuania.

Tayfun Ozcelik, Professor of Human Genetics

Bilkent University, Department of Molecular Biology and Genetics, Ankara, Turkey.

Jorge Sequeiros, MD, Professor in Medical Genetics, Head of the Department of Human Genetics, University of Porto, Porto, Portugal.

Maria Soller, MD, PhD,

Department of Clinical Genetics,

Lund University Hospital, Lund, Sweden.

Lisbeth Tranebjærg, MD, PhD, Professor in Genetic

Audiology, Department of Audiology, H:S Bispebjerg

Hospital and Wilhem Johannsen Centre of Functional

Genomics, University of Copenhagen, Denmark. 